\title{
PENDIDIKAN ANAK DALAM TRILOGI KEILMUAN PENDIDIKAN AGAMA ISLAM
}

\author{
Muhammad Nur Asmawi
}

\begin{abstract}
Religion (Islam) and education are two things which are interrelated. Through religion, humans are formed into whole people in accordance with the values of Islamic teachings. The development process is through education because through education, children will become more mature and more capable both in terms of intelligence and mental attitude. Religion is intended to form a complete human being by directing children to become people of faith and piety. The implementation of scientific trilogy of Islamic Religious Education is described in five aspects of Islamic Religious education, namely: aspects of the Koran-Hadith, aspects of aqidah/faith, aspects of morals, aspects of fiqhi/worship, and aspects of history/history of Islamic civilization. Aqeedah material emphasizes the formation of the belief that God is the origin and purpose of human life. Moral material is directed to prepare students to have Islamic morals and ethics as a whole person of Muslims and put into practice in their daily lives.
\end{abstract}

Keywords : Children's education, trilogy, Islamic Education

\section{PENDAHULUAN}

Pendidikan Islam tidak bisa diartikan pendidikan yang mengajarkan Islam secara formal ritual atau normatif saja seperti materi tentang baca tulis Alquran, tata cara sholat, syarat rukun sholat, puasa, zakat, haji, umroh, iman kepada Allah, iman kepada Rasulullah. Pendidikan Islam adalah materi yang berkaitan dengan pengetahuan, etika manusia dalam menghadapi problem kehidupan di dunia dan akherat. ${ }^{1}$ Pendidikan agama Islam adalah memuat materi yang mengajarkan tentang tata cara bagaimana agar manusia mampu mencapai kebahagiaan di dunia dan akherat.

Agama (Islam) dan pendidikan adalah dua hal yang satu sama lain saling berhubungan. Melalui agama, manusia diarahkan menjadi manusia seutuhnya

${ }^{1}$ M. Saekhan Muchith, Problem Keilmuan Pendidikan Agama Islam, Jurnal Penelitian, Vo.9, No.2, Agustus 2015, 389 
152 | MUSAWA, Vol. 11 No. 2 Desember 2019 : 151 - 164

sesuai dengan nilai-nilai ajaran Islam. Proses pengembangannya adalah melalui pendidikan. Karena melalui pendidikan, anak akan menjadi lebih dewasa dan lebih mampu baik dari segi kecerdasannya maupun sikap mentalnya. Agama dimaksudkan untuk membentuk manusia Indonesia seutuhnya dengan mengarahkan anak menjadi manusia Indonesia yang beriman dan bertaqwa. ${ }^{2}$

Di samping itu juga, agama memberikan tuntunan yang jelas kepada manusia, mana yang baik dan mana yang buruk, mana yang harus dikerjakan dan mana pula yang harus ditinggalkan, mana yang menguntungkan dan mana yang merugikan. Harapan yang paling fundamental dengan adanya pendidikan agama Islam di sekolah/madrasah adalah diharapkan lahirnya sosok-sosok yang benarbenar mampu memahami substansi agama itu sendiri sekaligus dapat mengimplementasikannya dalam kehidupan dengan indikasi prilaku dan kesalehan individual dan sosial yang nyata. ${ }^{3}$

Pendidikan Agama Islam meliputi semua pengetahuan, pengalaman dan realitas yang terjadi di alam raya ini, mulai dari bagaimana memahami atau memaknai, sampai bagaimana memfungsikan apa yang ada di bumi ini untuk kemashlahatan atau kemanfaatan bagi manusia. Pendidikan agama Islam berada di atas pendidikan lainnya, karena pendidikan Islam mewarnai, mengilhami atau memberi inspirasi ilmu-ilmu lainnya seperti ilmu sosiologi, psikologi, manajemen, kewarganegaraan, kependudukan, politik, fisika, biologi, matematika, musik, olahraga dan lainnya.

Pendidikan Agama Islam (PAI) di madrasah, meliputi: Aqidah-Akhlaq, Qur'an-Hadis, Fiqh, dan Sejarah Kebudayaan Islam (SKI). ${ }^{4}$ Pendidikan agama itu

\footnotetext{
${ }^{2}$ Rahardjo, Islam Dan Transformasi Budaya (Jakarta: PT. Dana Bhakti PrimaYasa, 2002), 360 .

3 Ani Nur Hidayati, "IMPLEMENTASI KURIKULUM 2013 REVISI 2017 PADA PENDIDIKAN AGAMA ISLAM," last modified 2017, accessed May 15, 2018, https://bdksemarang.kemenag.go.id/implementasi-kurikulum-2013-revisi-2017-pada-pendidikanagama-islam/.

${ }^{4}$ M. Zainuddin, "ANALISIS PENGEMBANGAN MATERI PENDIDIKAN AGAMA ISLAM (PAI)," last modified 2013, accessed May 25, 2018, http://zainuddin.lecturer.uinmalang.ac.id/2013/11/08/analisis-pengembangan-materi-pendidikan-agama-islam-pai/.
} 
sendiri akan selalu terintegrasi dalam setiap pembelajaran, baik pembelajaran langsung maupun tidak langsung dalam semua mata pelajaran. ${ }^{5}$

Pemahaman tentang Pendidikan Agama Islam (PAI) di sekolah/ perguruan Tinggi dapat dilihat dari dua sudut pandang, yaitu PAI sebagai aktivitas dan PAI sebagai fenomena. Pada domain yang pertama dimaksudkan bahwa PAI sebagai upaya yang dilakukan secara sadar dirancang untuk membantu seseorang atau sekelompok orang dalam mengembangkan pandangan hidup dan kehidupannya, sikap hidup, dan keterampilan hidup, baik yang bersifat manual (petunjuk praktis) maupun mental dan sosial yang bernafaskan atau dijiwai oleh ajaran dan nilai-nilai Islam. ${ }^{6}$ Sedangkan PAI sebagai fenomena merupakan peristiwa perjumpaan antara dua orang atau lebih dan/atau penciptaan suasana yang dampaknya kepada berkembangnya suatu pandangan hidup yang bernafaskan atau dijiwai oleh ajaranajaran Islam, yang diwujudkan dalam sikap hidup serta keterampilan hidup pada salah satu atau beberapa pihak. ${ }^{7}$ Oleh kerena itu makalah ini mengemukakan tentang bagaimana trilogi keilmuan Pendidikan agama Islam dan dan impelementasinya pada pembelajaran di Sekolah/madrasah.

\section{PEMBAHASAN}

\section{Rekonstruksi Trilogi Keilmuan Pendidikan Agama Islam}

Trilogi keilmuan agama Islam sebagaimana dijumpai dalam terminologi Pendidikan Agama Islam di sekolah, menurut Amin Abdullah adalah aqidahsebenarnya adalah diskusi tentang kalam/teologi, ibadah-mewakili fiqh atau syari’ah- dan akhlaq-yang akarnya adalah tasawwuf. Hubungan intern antar anggota rumpun keilmuan agama Islam sesungguhnya berkelitkelindan, karena tidak dapat dipisahkan begitu saja antara yang satu dengan lainnya.

Dari kutipan tersebut nampak jelas usaha yang dilakukan oleh Amin, yang ingin melakukan perluasan bidang ilmu-ilmu keagamaan Islam yang ada di kluster

\footnotetext{
5 Hidayati, “IMPLEMENTASI KURIKULUM 2013 REVISI 2017 PADA PENDIDIKAN AGAMA ISLAM."

${ }^{6}$ Hanafi, "Pengembangan Kurikulum Perguruan Tinggi Agama Islam," Islamuna 2, no. 1 (2014): 255-296.

${ }^{7}$ Hanafi, "Pengembangan Kurikulum Perguruan Tinggi Agama Islam."
} 
154 | MUSAWA, Vol. 11 No. 2 Desember 2019 : 151 - 164

ke 3 "Spider web" yaitu trilogi keilmuan Islam: kalam, fiqh dan tasawuf. Perluasan bidang ini dilakukan dengan cara mendialogkannya dengan konsep-konsep keilmuan, lebih tepatnya filsafat keilmuan yang digagas oleh para pemikir Muslim kontemporer, seperti Abdullah Saeed, Jasser Audah, Fethulleh Gulen dan lain-lain. Trilogi keilmuan agama Islam ini dapat diparalelkan dengan hubungan trilogis antara iman (kalam), Ilmu (fiqh), dan amal (tasawuf) sebagaimana dalam QS. AlMujadalah (58) :11 yang juga dapat digunakan sebagai landasan ontologis paradigma integrasi-interkoneksi.

Perluasan bidang trilogi keilmuan Islam yang digagas oleh Amin Abdullah adalah bidang (ibadah) fiqh ke hukum Islam sistemik. Menurutnya, tanpa melibatkan dan menggunakan ide-ide, pikiran-pikiran, hasil penelitian yang relevan dari disiplin ilmu yang lain, seperti sosiologi, antropologi, psikologi, komunikasi dan sains pada umumnya, maka penelitian yang terkait dengan teori fundamental fiqh akan selamanya 'terjebak' dalam batas-batas literatur-literatur tradisional berikut manuskrip-manuskripnya, dan pemikiran fiqhi akan terus menerus 'tertinggal' (outdated) dalam membangun basis teorinya dan praktik-praktik pelaksanaan hukum di lapangan dan praktik pendidikan agama Islam dalam kehidupan sehari-hari di tengah-tengah masyarakat multikultural-multireligi seperti di era global sekarang ini. Untuk merekonstruksi dan mempertautkan kembali trilogi keilmuan agama Islam ini, Amin menggunakan pendekatan ijtihad progressif-nya Abdullah Saeed, pendekatan system-nya Jasser Auda (utuh, kognisi saling terkait dan keterbukaan), spiritualitas sains-nya Fethullah Gulen.

Sehingga upaya untuk membangun paradigma baru dan merekonstruksi epistemologi keilmuan fiqhi (hukum Islam), terlebih lagi ilmu pendidikan Islam di era disrupsi ini, meniscayakan pendekatan multidisipliner, interdisipliner bahkan transdisipliner. ahli fiqhi atau hukum Islam dan tenaga pendidikan Islam kontemporer mesti familiar dengan studi sosial dan sensitif dengan isu-isu humanities kontemporer secara lebih dekat.

Secara intelektual, upaya ini sangat urgen mengingat keberhasilan dan kegagalannya tidak hanya berakibat pada pola pembentukan pemikiran fiqhi dan 
praktik hukum Islam (syari`ah) dalam masyarakat luas, tetapi juga akan berpengaruh secara langsung terhadap bangunan materi pendidikan dan pengajaran agama Islam di setiap lapis dan jenjangnya, rumusan teori, metode dan pendekatan, bahkan pada kurikulum, silabi dan literatur yang digunakan dalam perkuliahan di berbagai jenjang dan fakultas. Pada gilirannya akan membentuk dan mengubah pola pikir para pemimpin komunitas muslim dan pola hubungan sosialkemasyarakatan secara luas dalam kehidupan masyarakat muslim penggunanya.

Selanjutnya, rekonstruksi trilogi keilmuan Islam dari (akhlak) tasawuf ke spritualitas sains. Hubungan trilogi keilmuan agama Islam sebagaimana telah disebutkan yaitu antara kalam, fiqhi, dan tasawuf dalam salah satu ayat Alquran, identik dengan hubungan trilogi antara iman, ilmu dan amal. Dalam perspektif hadis, hubungan trilogi keilmuan agama Islam tersebut juga identik dengan hubungan trilogis antara Islam (fiqh), iman (kalam) dan ihsan (tasawuf).

Terkait dengan hubungan ketiganya, sudah merupakan hukum sejarah keilmuan, jika satu cabang ilmu telah berkembang menjadi satu disiplin tersendiri dengan tokoh-tokoh pendukung dan pencetusnya yang solid (arkān imān menjadi cakupan teologi/kalam dan filsafat: arkān Islām menjadi bidang garap fiqh-nya fuqaha dengan lembaga-lembaga seperti mufti, peradilan agama, dan sebagainya; dan ihsān menjadi bidang garap tasawuf, yang kemudian dalam perkembangan selanjutnya menjadi kolompok-kolompok terekat.

Maka, secara keagamaan hubungan trilogi yang dimaksud adalah antara Iman, Islam dan Ihsan, sedangkan secara keilmuan hubungan ini identik dengan fiqhi, kalam dan tasawuf. Perguruan tinggi Islam sejatinya mampu 'memekarkan' visi dan misi keagamaannya ke wilayah keilmuan dengan cara mengembangkan ketiga keilmuan agama Islam tersebut. Waryani menilai bahwa Amin Abdullah mencoba memekarkan fiqhi ke arah hukum Islam sistemik, kalam ke arah teologi progressif-Negosiatif dan filsafat etik, dan tasawuf ke arah spiritualitas sains. Dengan demikian, fakultas 'Islam' atau fakultas 'fiqhi' dapat dipresentasikan oleh Fakultas Syari'ah (dan Hukum); Fakultas 'Iman' atau Fakultas 'kalam' dapat dipresentasikan oleh Fakultas Ushuluddin (dan Pemikiran Islam), dan fakultas 
156 | MUSAWA, Vol. 11 No. 2 Desember 2019 : 151 - 164

'ihsan' atau fakultas tasawuf dapat dipresentasikan oleh Fakultas Adab (dan ilmu budaya)-adab dalam arti akhlak atau etik, sedangkan posisi Fakultas Dakwah dan Komunikasinya adalah sebagai ‘juru bicara’ keagamaannya, dan Fakultas Tarbiyah (dan Keguruan)nya adalah sebagai 'juru bicara’ keilmuannya.

\section{Pendidikan anak dalam trilogi keilmuan Pendidikan Agama Islam}

Dalam kurikulum 2013, Pendidikan Agama Islam di sekolah dasar dan sekolah menengah digabung dengan Pendidikan Budi Pekerti, sehingga namanya menjadi Pendidikan Agama Islam dan Budi Pekerti. Implementasi trilogi keilmuan Pendidikan Agama Islam diuraikan dalam lima aspek pendidikan Agama Islam, yaitu: aspek Alquran-Hadis, aspek aqidah/keimanan, aspek akhlak, aspek fiqhi/ibadah, dan aspek tarikh/sejarah peradaban Islam. Sebagai contoh, implementasi trilogi keilmuan PAI tersebut pada SMA kelas X dengan cakupan materi sebagai berikut:

1. Aspek Alquran-Hadis meliputi:

a. Alquran surah al-Hujurat/49: 10 dan 12 serta hadis tentang kontrol diri, prasangka baik dan persaudaraan.

b. Alquran surah al-Isra`/17:32 dan QS. An-Nur/24: 2 serta hadis tentang larangan pergaulan bebas dan perbuatan zina.

2. Aspek aqidah/keimanan meliputi:

a. al- Asma`u al-husna: al-Karim, al-Mu`min, al-Wakil, al-Matin, al-Jami`, alAdl, dan al-Akhir.

b. Iman kepada malaikat-malaikat Allah Swt.

3. Aspek Akhlak meliputi:

a. Ketentuan berpakaian sesuai syari’at Islam.

b. Manfaat kejujuran dalam kehidupan sehari-hari.

c. Semangat keilmuan.

4. Aspek fiqhi/ibadah meliputi:

a. Kedudukan Alquran, Hadis, dan ijtihad sebagai sumber hukum Islam.

b. Hikmah ibadah haji, zakat dan wakaf bagi individu dan masyarakat. 
5. Aspek tarikh/sejarah peradaban Islam meliputi:

a. Substansi, strategi dan penyebab keberhasilan dakwah Nabi Muhammad saw di Makkah.

b. Substansi, strategi dan keberhasilan dakwah Nabi Muhammad saw.di Madinah.

Dalam standar proses, pembelajaran dilakukan dengan memaksimalkan kemampuan anak melalui pendekatan saintifik dan melalui langkah-langkah mengamati, bertanya, mencoba, menalar dan mengkomunikasikan. Selanjutnya langka-langkah tersebut diintegrasikan ke dalam penyusunan buku ajar melalui proses dan rubrikasi Membuka Relung Hati (mengamati), mengkritisi sekitar kita (bertanya), Memperkaya Khazanah Peserta Didik (menalar), Menerapkan Prilaku Mulia (mencoba dan mengomunikasikan).

Pendidikan Agama Islam (PAI) adalah pendidikan yang terencana untuk menyiapkan peserta didik dalam meyakini, memahami, manghayati, dan mengamalkan ajaran Islam melalui kegiatan bimbingan, pengajaran dan atau latihan. Implementasi trilogi keilmuan Pendidikan Agama Islam (PAI) meliputi: Akidah-Akhlaq, Qur'an-Hadis, Fiqh, dan Sejarah Kebudayaan Islam (SKI). Materi Aqidah adalah bagian dari mata pelajaran PAI yang memberikan penekanan pada pembinaan keyakinan bahwa Tuhan adalah asal-usul dan tujuan hidup manusia. Materi Aqidah menekankan pada kemampuan memahami dan mempertahankan keyakinan/keimanan yang benar serta menghayati dan mengamalkan nilai-nilai yang terkandung dalam nama-nama Allah Swt. (al-asma' al-husna).

Pada materi Aqidah, mempelajari sifat 20 Tuhan (Aqīdat al-Awwām) atau mengenalkan sifat-sifat Tuhan yang 99 sebagaimana yang disebutkan dalam Alquran yang dikenal dengan al-asma' al-husna perlu diarahkan pada dimensi empirik misalnya dengan menjelaskan kepada anak bahwa Tuhan itu memiliki sifat Rahman (Maha pengasih), jadi manusia harus optimis dalam menjalani hidup di dunia ini. Sifat Rahman atau kasih sayang Tuhan itu diberikan kepada semua hamba-Nya, tanpa pandang bulu, tanpa diskriminiatif, baik hamba yang mukmin maupun yang tidak, namun Allah Swt. hanya memberikan kasih sayang (Rahim- 
158 | MUSAWA, Vol. 11 No. 2 Desember 2019 : 151 - 164

Nya) di akhirat kelak khusus kepada yang Mukmin saja. Oleh sebab itu, jika di dunia ini orang non-Mukmin belajar kedokteran, maka mereka akan menjadi Dokter. Namun jika orang Mukmin sendiri tidak belajar kedokteran, tetapi belajar ilmu klenik, maka mereka akan menjadi Dukun. Demikian pula, jika orang nonMukmin bekerja keras mengikuti hukum ekonomi, maka mereka akan menjadi kaya, ini hukum yang berlaku di dunia. Begitu pun sebaliknya, jika orang Mukmin malas-malasan bekerja, maka mereka menjadi miskin.

Contoh lain misalnya, Tuhan itu memiliki sifat Ghafur, Maha Pengampun, karena itu, manusia tidak perlu putus asa, walau sudah berbuat dosa kita bisa minta ampun kepada-Nya, meski begitu manusia tidak boleh terus menerus berbuat dosa kemudian minta ampun. Tuhan itu memiliki sifat Wadud (santun), karena itu Dia tidak bakal menerlantarkan. Demikian pula dengan sifat Tuhan yang seram-seram, seperti Tuhan itu Maha Perkasa (Jabbar) dan Pendendam (Dzun Tiqam), hal ini agar manusia tidak memperlakukan kewajiban-kewajiban Tuhan semaunya.

Sifat-sifat Tuhan yang terkandung dalam al-asmā' al-husna itulah yang seharusnya memberikan dampak psikologis bagi peserta didik. Ketika menjelaskan sifat Mahamengetahuinya Tuhan (al-'alim) dan kemahabijaksanaan-Nya (alhakim) bisa dijelaskan melalui fenomena empirik. Misalnya diungkapkan sebuah kisah seorang Musafir yang sedang berteduh di bawah pohon beringin besar lagi rindang yang buahnya kecil-kecil, sementara itu di hadapannya tumbuh buah semangka besar yang batangnya kecil merambat di tanah. Ketika seorang Musafir itu terbersit di hatinya untuk menganggap kenyataan ini janggal, maka serta merta ia kejatuhan buah beringin itu. Seketika itu juga ia sadar, bahwa apa yang diciptakan Tuhan itu benar adanya. Karena itu, perlu memperkaya mata pelajaran Aqidah dengan pengembangan-pengembangan seperti ini, bahwa untuk menunjukkan kemahakuasaan Allah Swt. cukup ditunjukkan pada penciptaan (makhluk)-Nya yang terhampar di jagat raya ini (tafakkaru fi khalqillah walā tafakkaru fi zātihi). Masih banyak contoh lain yang bisa dikembangkan terkait dengan ini, sehingga aspek afektif dan psikomotor dapat dicapai sesuai dengan tujuan pembelajaran. 
Sementara itu materi Qur'an-Hadis menekankan pada kemampuan baca tulis yang baik dan benar, memahami makna secara tekstual dan kontekstual, serta mengamalkan kandungannya dalam kehidupan sehari-hari. Alquran merupakan wahyu Tuhan yang kebenarannya bersifat absolut. Jika dilihat dari aspek psikologis -dalam konteks mempelajari Alquran- belajar membaca dengan benar dan baik, serta menghafal ayat-ayat Alquran -terutama surat-surat pendek- akan lebih melekat dan bertahan lama jika dimulai pada usia SD/MI (6 - 12 tahun). Belajar membaca dan menulis serta menghafal Alquran tersebut perlu dilakukan secara intensif. Jika dilakukan pada hari tertentu (hari senin jam pertama dan kedua misalnya, karena PAI hanya 2 jam pelajaran) kemudian disusul pada hari senin berikutnya dan seterusnya sampai beberapa semester, maka kecil kemungkinannya untuk dapat melekat dan tahan lama dalam ingatannya, terutama jika tidak didukung oleh pendidikan agama dalam keluarga dan masyarakat (seperti pendidikan agama pada TPQ/TPA/TKA dan sebagainya).

Dilihat dari aspek psikologi agama, bahwa siswa MI/SD yang sudah aqil baligh, berkewajiban untuk menjalankan ibadah shalat (mukallaf). Pada periode ini anak membutuhkan pemahaman Alquran baik dari segi arti lafdhiyah (tekstual) maupun kandungan makna dan mengaitkannya dengan fenomena alam, sosial, budaya, politik, ekonomi dan lain-lainnya (kontekstual), sehingga dapat menambah ke-khusyu'an dalam beribadah dan mampu membangun kesadaran beragama (religious conciousness) anak. Al-Quran dengan demikian benar-benar menjadi hudan (petunjuk dalam kehidupan), furqan (pembeda antara yang haq dan bathil, antara yang benar dan salah, dan antara yang baik dan buruk), obat psikologis bagi manusia beriman (syifā' mā fī al-shudūr). Tujuan pengembangan materi ini adalah sebagai upaya mencari alternatif untuk meningkatkan hasil belajar dan transfer belajar, memberi dan meningkatkan wawasan guru terhadap materi pembelajaran agar dicapai hasil belajar yang maksimal.

Alquran-Hadis merupakan sumber utama ajaran Islam, dan juga merupakan sumber Aqidah-Akhlak, Syari'ah/Fiqh (ibadah, muamalah), sehingga kajiannya berada di setiap unsur tersebut. Aqidah (ushuluddin) atau keimanan merupakan akar atau pokok agama. Syariah/Fiqh (ibadah, muamalah) dan Akhlak bertitik tolak dari 
160 | MUSAWA, Vol. 11 No. 2 Desember 2019 : 151 - 164

Aqidah, yakni sebagai manifestasi dan konsekuensi dari Aqidah (keimanan dan keyakinan hidup). Syari'ah/Fiqh merupakan sistem norma (aturan) yang mengatur hubungan manusia dengan Allah, sesama manusia dan dengan makhluk lainnya. Akhlaq merupakan aspek sikap hidup atau kepribadian hidup manusia, dalam arti bagaimana sistem norma yang mengatur hubungan manusia dengan Allah (ibadah dalam arti khas) dan hubungan manusia dengan manusia dan lainnya (muamalah) itu menjadi sikap hidup dan kepribadian hidup manusia dalam menjalankan sistem kehidupannya (politik, ekonomi, sosial, pendidikan, kekeluargaan, kebudayaan/seni, iptek, olahraga/kesehatan, dan lain-lain) yang dilandasi oleh Aqidah yang kokoh. Sedangkan tarikh (sejarah) Kebudayaan Islam merupakan perkembangan perjalanan hidup manusia muslim dari masa ke masa dalam usaha bersyariah (beribadah dan bermuamalah) dan berakhlak serta dalam mengembangkan sistem kehidupannya yang juga dilandasi oleh Aqidah.

Aqidah sebagai sebuah objek kajian akademik meliputi beberapa agenda pembahasan, yaitu pembahasan yang berhubungan dengan beberapa aspek seperti aspek Ilahiyah (ketuhanan), nubuwah, dan ruhaniyah arkanul iman (rukun iman). Pertama, pembahasan yang berkaitan dengan aspek ilahiyah meliputi segala yang berkaitan dengan Tuhan, seperti wujud Allah, sifat-sifat Allah, perbuatanperbuatan, dan nama-nama-Nya. Kedua, pembahasan tentang kenabian (nubuwah) yang berkaitan dengan Nabi dan Rasul, kitab-kitab Allah yang diturunkan melalui Nabi dan Rasul Allah serta kemukjizatanya. Ketiga, aspek ruhaniyah membicarakan tentang segala sesuatu yang bersifat transcendental atau metafisik seperti ruh, malaikat, jin, iblis, dan setan. Selain tiga aspek tersebut, aspek keempat yang menjadi lingkup kajian dalam aqidah adalah sam'iyah yang membahas tentang sesuatu yang dalil-dalil naqli berupa al-Qur'ean dan Sunnah, alam barzakh, akhirat, azab, dan kubur.

Sementara itu materi Akhlak adalah bagian dari trilogi keilmuan PAI yang diarahkan untuk menyiapkan peserta didik agar memiliki moral dan etika Islam sebagai keseluruan pribadi Muslim dan dimalkan dalam kehidupan sehari-hari. Materi Akhlaq menekankan pada pembiasaan untuk menerapkan akhlak terpuji (alakhlaq al-mahmudah) dan menjauhi akhlak tercela (al-akhlaq al-mazmumah) dalam 
kehidupan sehari-hari. Akhlaq mempelajari relasi antara manusia dengan Tuhan, manusia dengan manusia, dan manusia dengan alam semesta (Ihsan). Relasi atau hubungan ketiganya ini harus harmonis sebagaimana yang ditunjukkan dalam QS.al-Qashash: 77. Bahwa manusia harus mentaati perintah Allah dan menjauhi segala larangan-Nya, berbuat baik kepada sesama manusia dan juga makhluk lain, termasuk mampu menjaga dan merawat kelestraian alam sebagai anugerah Allah Swt. ini.

Materi Fiqh adalah bagian mata pelajaran PAI yang diarahkan untuk menyiapkan peserta didik agar dapat mengenal, memahami, menghayati, dan mengamalkan hukum Islam, yang kemudian menjadi dasar pandangan hidupnya (way of life) melalui kegiatan bimbingan, pengajaran, latihan, serta pengalaman. Materi Fiqh menekankan pada kemampuan cara melaksanakan ibadah dan muamalah yang benar dan baik, bersifat fleksibel dan kontekstual. Oleh sebab itu, hal-hal yang terkait dengan ibadah mahdhah sedapat mungkin dijelaskan sesuai dengan perkembangan ilmu pengetahuan modern, misalnya soal makna wudhu' dan shalat ditinjau dari aspek kesehatan, psikologis dan sosial. Demikian pula tentang najis dan haram yang harus dijauhi oleh umat Islam. Semua itu perlu dijelaskan dalam konteks kehidupan kontemporer.

Sedangkan materi Tarikh atau Sejarah Kebudayaan Islam (SKI) adalah bagian dari mata pelajaran PAI yang diarahkan untuk menyiapkan peserta didik agar memiliki pemahaman terhadap apa yang telah diperbuat oleh Islam dan kaum Muslimin sebagai katalisator proses perubahan sesuai dengan tahapan kehidupan mereka pada masing-masing waktu, tempat dan masa, untuk dijadikan sebagai pedoman hidup ke depan bagi umat Islam. Materi SKI juga menekankan pada kemampuan mengambil hikmah dan pelajaran ('ibrah) dari peristiwa-peristiwa bersejarah pada masa lalu yang menyangkut berbagai aspek: sosial, budaya, politik, ekonomi, iptek dan seterusnya, serta meneladani sifat dan sikap para tokoh berprestasi, dari Nabi Muhammad Saw., para sahabat hingga para tokoh sesudahnya bagi pengembangan kebudayaan dan peradaban Islam masa kini. Prinsip yang digunakan dalam melihat sejarah masa lalu adalah: "Meneladani hal-hal yang baik dan meninggalkan hal-hal yang buruk serta mengambil hikmah dan 'ibrah dari 
162 | MUSAWA, Vol. 11 No. 2 Desember 2019 : 151 - 164

peristiwa masa lalu tersebut untuk pelajaran masa kini dan mendatang". Pelajaran SKI juga harus berwawasan transformatif-inovatif dan dinamis.

Oleh karena itu, dalam kurikulum 2013 edisi revisi 2017 dinyatakan bahwa mata pelajaran PAI dengan trilogi keilmuannya menjadi mata pelajaran yang memiliki muatan KD yang dijabarkan ke dalam indikator untuk komponen sikap spriritual dan sikap sosial. KD-KD untuk mata pelajaran Pendidikan Agama Islam diatur dalam Keputusan Menteri Agama No 165 tahun 2014 namun dalam implementasi pembelajaran mengikuti ketentuan standar proses yang terbaru dan berlaku sesuai Permendikbud no. 22 Tahun 2014 yang memprasyaratkan adanya pengintegrasian 4C (Creative, Critical Thinking, Communicative, dan Collaborative); Mengintegrasikan HOTS (Higher Order Thinking Skill); Gerakan literasi sekolah.

\section{PENUTUP}

Trilogi keilmuan agama Islam yang memuat aqidah, ibadah dan akhlak sebagaimana dijumpai dalam terminologi Pendidikan Agama Islam di sekolah, adalah aqidah-sebenarnya adalah diskusi tentang kalam/teologi, ibadah-mewakili fiqh atau syari ah- dan akhlaq-yang akarnya adalah tasawwuf. Hubungan intern antar anggota rumpun keilmuan agama Islam sesungguhnya berkelitkelindan, karena tidak dapat dipisahkan begitu saja antara yang satu dengan lainnya. Maka, secara keagamaan hubungan trilogi yang dimaksud adalah antara Iman, Islam dan Ihsan, sedangkan secara keilmuan hubungan ini identik dengan fiqhi, kalam dan tasawuf. Perguruan tinggi Islam sejatinya mampu 'memekarkan' visi dan misi keagamaannya ke wilayah keilmuan dengan cara mengembangkan ketiga keilmuan agama Islam tersebut.

Implementasi trilogi keilmuan Pendidikan Agama Islam (PAI) meliputi: Akidah-Akhlaq, Qur'an-Hadis, Fiqh, dan Sejarah Kebudayaan Islam (SKI). Materi Aqidah adalah bagian dari mata pelajaran PAI yang memberikan penekanan pada pembinaan keyakinan bahwa Tuhan adalah asal-usul dan tujuan hidup manusia. Materi Aqidah menekankan pada kemampuan memahami dan mempertahankan 
keyakinan/keimanan yang benar serta menghayati dan mengamalkan nilai-nilai yang terkandung dalam nama-nama Allah Swt. (al-asma’al-husna). Materi Qur'anHadis adalah bagian dari trilogi keilmuan PAI menekankan pada kemampuan baca tulis yang baik dan benar, memahami makna secara tekstual dan kontekstual, serta mengamalkan kandungannya dalam kehidupan sehari-hari. Materi Akhlak yang diarahkan untuk menyiapkan peserta didik agar memiliki moral dan etika Islam sebagai keseluruan pribadi Muslim dan dimalkan dalam kesehariannya. Sedangkan materi Tarikh atau Sejarah Kebudayaan Islam (SKI) adalah bagian dari mata pelajaran PAI yang diarahkan untuk menyiapkan peserta didik agar memiliki pemahaman terhadap apa yang telah diperbuat oleh Islam dan kaum Muslimin sebagai katalisator proses perubahan.

\section{DAFTAR PUSTAKA}

Abdullah, M. Amin, Epistemologi Ilmu Pro(f)Etik: Apa Yang Terlupakan Dari Ilmu-Ilmu Sekuler ,Disampaikan dalam sarasehan ilmu profetik II di Ruang Sidang A 1t.5 Sekolah Pascasarjana UGM, 2011.

,Rekonstruksi Filsafat Pendidikan Islam Pada Era Perubahan Sosial: Membangun Paradigma Filsafat Keilmuan Dan Pendidikan Agama Islam Disampaikan Pada Workshop Kurikulum Program Doktor Pendidikan Agama Islam, Universitas Muhammadiyah Malang 18 Mei 2013 (Malang, 2013).

Tasawuf: Dimensi Batin Agama Islam, Yogyakarta, 1991.

al-Gazali, Muhammad, Al-Janib Al Afifi Min Al-Islam, Kairo: Dar al-Da`wah, 1990.

Hanafi, "Pengembangan Kurikulum Perguruan Tinggi Agama Islam," Islamuna 2, no. 1 (2014.

Hidayati, Ani Nur, "IMPLEMENTASI KURIKULUM 2013 REVISI 2017 PADA PENDIDIKAN AGAMA ISLAM," last modified 2017, accessed May 15, 2018, https://bdksemarang.kemenag.go.id/implementasi-kurikulum-2013revisi-2017-pada-pendidikan-agama-islam/.

Kementerian Pendidikan dan Kebudayaan RI, Pendidikan Agama Islam dan Budi Pekerti untuk SMA/MA/SMK/MAK kelas $X$, Jakarta: Kementrian Pendidikan dan Kebudayaan, 2016

Mahfud, Rois, Al- Islam Pendidikan Agama Islam, Bandung: Erlangga, 2011

Muchith, M. Saekhan, Problem Keilmuan Pendidikan Agama Islam, Jurnal Penelitian, Vo.9, No.2, Agustus 2015, 389 
164 | MUSAWA, Vol. 11 No. 2 Desember 2019 : 151 - 164

Rahardjo, Islam Dan Transformasi Budaya (Jakarta: PT. Dana Bhakti PrimaYasa, 2002), 360.

Riyanto, WAryani Fajar, Integrasi-Interkoneksi Keilmuan Biografi Intelektual M. Amin Abdullah (1953-...) Person, Knowledge and Institution, Yogyakarta: SUKA-Press, 2013.

Saebani, Beni Ahmad, Filsafat Hukum Islam, Bandung: Pustaka Setia, 2007.

Suyuti, Ahmad, Islam Progresif Kontemporer: Telaah Pemikiran Abdulah Saeed, Jurnal Akademika, Volume 6 Nomor 1 Juni 2012.

Zainuddin, M., Paradigma Pendidikan Terpadu: Menuju Pembentukan Generasi Ulul Albab, Malang, UIN Press, 2008.

"ANALISIS PENGEMBANGAN MATERI PENDIDIKAN AGAMA ISLAM (PAI)," last modified 2013, accessed May 25, 2018, http://zainuddin.lecturer.uin-malang.ac.id/2013/11/08/analisispengembangan-materi-pendidikan-agama-islam-pai/. 